DOI: $10.2478 / v 10057-009-0007-4$

\author{
HRISTO KYUCHUKOV \\ Constantine the Philosopher University, Nitra \\ JILL DE VILLIERS \\ Smith College, Northampton
}

\author{
THEORY OF MIND AND EVIDENTIALITY \\ IN ROMANI-BULGARIAN BILINGUAL CHILDREN
}

\begin{abstract}
The paper reports two studies of the development of false belief reasoning in bilingual Roma children in Bulgaria. No previous work has considered Roma children. Two studies were conducted, and in the second study the Roma children spoke a dialect of Romani that contains evidential markers, as does Bulgarian, their second language. Results reveal no advantage of bilingualism, and similar results with age to that found in other groups across the world. The bilingual group had better understanding of evidentials than the monolingual Bulgarian group, possibly related to the linguistic character of the markings. There is contradictory evidence about the relation of ToM and understanding of evidentiality.

Key words: Theory of Mind, bilingualism, Romani language, evidentiality
\end{abstract}

\title{
Introduction
}

\section{Language and Theory of Mind}

In the last decade or so there has been increased interest in the understanding of Theory of Mind (ToM) in bilingual children. There is no clear consensus yet that bilingualism in children helps or not or not for earlier understanding of ToM tasks. Some authors have proposed that the existence of two language systems in children might help them to understand the classic ToM task, namely false belief reasoning, at earlier age (Bialystok \& Senman, 2004).

There are several possible reasons why the language development of the child might influence the course of Theory of Mind development, well reviewed in Astington \& Baird (2005), and the meta-analysis by Milligan, Astington and Dack (2007). In general, the more vocabulary and syntax a child knows, the more likely $\mathrm{s} /$ he is to pass False Belief tasks. There are several competing explanations of this

Address for correspondence: Hristo Kyuchukov, UKF-FSVaZ, Kraskova 1, 94974 Nitra, Slovakia. E-mail: hkyuchukov@ukf.sk 
correlation. First, some argue that language is the source of knowledge about minds (Nelson, 2005; Harris, 2005, Woolfe, Want \& Siegal, 2002). It is through rich conversation that we learn to understand what other people know and think, and hence that different minds can contain different ideas and desires. Alternatively, some writers accentuate the fact that language is a tool for reasoning (Jaques \& Zelazo, 2005), and false belief reasoning tasks benefit from an explicit medium for reasoning, like other complex reasoning tasks. Third, the possibility exists that language is uniquely suited to representing other's belief states, or propositional attitudes (believe, know, think) because special kinds of sentences can represent the false propositions in someone else's mind:

\section{He thinks that the moon is made of cheese}

Imagery and discourse are poor alternatives for representing such a complex proposition, but language can do it easily with special structures, namely complements under mental verbs (de Villiers \& Pyers, 2002; de Villiers, 2005).

What happens in bilingual children? Bialystok (Bialystok \& Senman, 2004) argued that they might have an advantage, because bilingual children have to compare possible modes of responding whenever they speak, enhancing their executive function or metalinguistic skills (Carlson \& Meltzoff, 2008). On the other hand, bilingualism results in an initial slowing in the acquisition of each language, most noticeable in vocabulary (Pearson, Ferandez \& Oller, 1993). Results are mixed on whether bilingual children acquire ToM skills earlier than monolinguals in the literature to date, as the attempt to match them to monolinguals on vocabulary may create an atypical group (Goetz, 2003; Kovacs, 2009; de Villiers, de Villiers, \& Hobbs, 2009).

Our purpose in this paper is to contribute data to these questions from a group of bilingual children who speak Romani and Bulgarian, residing in Bulgaria. The languages in question are of additional interest because they both contain evidential markers (Aikenwald, 2004 Speas, 2004), a grammatical system marking speaker's source of knowledge that would seem to call attention to what the speaker and others know (Aksu-Koc, 1988, Papafragou \& Ozturk, 2007). For that reason we first introduce the special language properties involved.

\section{The languages in Bulgaria}

Romani and Bulgarian have been in a contact for last 800 years. Bulgarian is the official language of the country but Romani is spoken by approximately by $10 \%$ of the Bulgarian society. Bulgarian belongs to the South Slavic languages and Romani is a Balkanized New Indian Language. Romani is officially recognized as one of the 4 minority languages in the country (Armenian, Hebrew, Turkish and Romani) and it is allowed by the Ministry of Education to be taught in primary and secondary classes. 
The two languages Romani and Bulgarian share a few grammatical similarities, typical for the other Balkan languages. Romani and Bulgarian have been in contact with Turkish for more than 600 years and the two languages absorbed from Turkish evidential markings, i.e. a systematic grammatical marking of source of knowledge: witnessed/hearsay/inference. The morphemes are part of the verb morphology, connected to the aspect/tense system in complex ways. Evidentiality is always first person, that is, is about the speaker's source of knowledge (Speas, 2004; Aikhenwald, 2004). But like other internal state language, it must be learned by hearing others use it in context. For that reason, evidentiality is potentially connected to Theory of Mind, as it entails marking as a natural matter of course in speaking who saw or didn't see, who knows and who doesn't know.

Not all dialects of Romani have strong evidential marking. In Study 1 below the children spoke the Romani dialect from the city of Sofia called the Erlija dialect. In this particular dialect the Past tense has the suffix - as, taken by some to be a witnessed evidential, but if so, it is not uniquely evidential. The research for Study 2 was done in North East part of Bulgaria where the Roma speak a different dialect, called the Xoraxano dialect. The witnessed forms are in the Past tense and they have a suffix - as, but the non-witnessed form is given with the uniquely evidential suffix -lem. The -as suffix shows that someone witnessed something and the -lem suffix shows that the subject did not witness something. So in the dialect of Romani spoken in North East Bulgaria among the Muslim Roma , the form -lem is unambiguously evidential in meaning, carrying the meaning of non-witnessed. In Bulgarian, the form $-l,-l a,-l o$ ( $3 \mathrm{sg}$.) is taken to be the evidential meaning non-witnessed, with the contrast as the form -she ( 3 sg. Past tense). All evidential morphology attaches to the main verb as suffixes.

\section{Acquisition of evidentials}

Studies so far have been done mostly on the acquisition of Turkish (Aksu-Koç \& Alici, 2000) and Korean (Choi, 1995) evidentials, with less work on Bulgarian (Fitneva, 2007) and Tibetan (de Villiers, Garfield, Gernet-Girard, Speas \& Roeper, 2009). The morphemes are used by young children $(>2)$, but not systematically understood in experimental tasks until considerably later. For example, Aksu-Koç (1988) found Turkish monolinguals understood the witnessed form (-dI) at about age 4-5, but the unwitnessed form (mIs) only at age six. Similar findings are reported by Ozturk \& Papafragou (2007) and Papafrago, Li, Choi and Han (2007) for Korean. Fitneva (2007, 2008) found Bulgarian monolinguals understood the contrasts at age six, though imperfectly. There has been no work until now on the acquisition of Romani evidentials.

\section{Research questions}

The research was undertaken to answer the following questions:

- How do Roma children do on ToM (specifically False Belief) tasks?

- How does mastery of ToM progress in bilingual versus monolingual children? 
- When are evidentiality markers comprehended in each language?

- What is the relation between understanding evidentiality markers and passing ToM?

The research was done with Roma children from Bulgaria. There were two studies that were done with children speaking different dialects of Romani. For the purposes of exposition it is most appropriate to discuss the design and tasks for the two studies first, and then the combined results.

\section{Methods}

\section{Study 1}

\section{Subjects}

In the first study 30 Romani- Bulgarian bilingual children from the city of Sofia participated. They were speakers of the Erlija dialect of Romani. The children were divided into three age groups of ten:

Group 1: 3;0-3;6 $(\mathrm{N}=10)$;

Group 2: 3;7-4;0 ( $=10)$;

Group 3: 4;1-4;6 ( $\mathrm{N}=10)$.

All children were tested in the natural home environment by a Roma woman, a member of the community, who was a native speaker of that particular dialect. The children were tested first in their mother tongue (L1) and then in their second language (L2), namely Bulgarian. In this study we also asked about parental education level as an index of socio-economic status, as the Roma are generally living on the margin of poverty in Bulgarian society as they do throughout Europe.

\section{Tasks}

The tasks given to the children are known from the scientific literature as classic False Belief Tasks (FB) (Wellman, Cross \& Watson, 2003). The content of the first FB task "Unexpected contents" is the following:

A closed empty box of chocolates is shown to the child. Inside of the box there is a biscuit. The child is asked what he thinks that there is in the box and then the box is opened and the child sees that there is a biscuit. Then the box is closed and the child is asked the following questions:

1) What did you think was the content of the box when you saw the box first? (1 point)

2) What did you see when we opened the box? (memory check)

3) What will the dog puppet think (which enters the scene) if we show the box to it? (1 point)

The content of the second FB task "Unseen Displacement" is the following:

Two puppets- the dog and the cat (the puppets are shown to the children and they act) - decided to make a cake. They put the cake in the cupboard. Then the 
cat told that she is going to take a walk and she leaves the house. In the meantime the dog decided to change the place of the cake and he moved it to the refrigerator. Then the child is asked control questions:

1) Where did the cat and the dog first put the cake?

2) Where is the cake now?

In the evening the cat comes home and she is very hungry and she wants to eat from the cake.

A false belief question and a justification:

3) Where she will look first for the cake? (1 point)

4) Why there? (1 point)

\section{Study 2}

In the second study some changes were made. First, the age groups of the Roma children were selected to be slightly older by six months, because the average age of the groups in Study 1 fell below the average age of success on false belief tasks found in met-analyses of data cross-linguistically (Wellman, Cross \& Liu, 2003). Secondly, in Study 2 a group of monolingual Bulgarian-speaking children was included for comparison purposes as no data on these tasks existed for this group. Thirdly, we decided to study a second dialect of Romani in which there is a clear evidential marker, -lem, unambiguously marking non-witnessed, not tense.

\section{Subjects}

Sixty Romani-Bulgarian bilingual children participated in the study, as well as sixty monolingual Bulgarian-speaking children. The children were distributed again into 3 groups as in the first study but with a slightly older age range:

Group 1: 3;7-4;0 ( $\mathrm{N}=40: 20$ Romani-Bulgarian, 20 Bulgarian)

Group 2: 4;1-4;6 ( $\mathrm{N}=40: 20$ Romani-Bulgarian, 20 Bulgarian)

Group 3: 4;7-5;0 ( $\mathrm{N}=40$ : 20 Romani-Bulgarian, 20 Bulgarian).

The children were tested in the kindergarten environment by native speakers who were teachers. In the second study the children were from North East Bulgaria, where the Roma speak a variety of Romani with a clear evidential marker -lem signifying non-witnessed. The bilinguals were tested first in the mother tongue of the children(L1) and then in their second language (L2) - Bulgarian.

Tasks

Children received the same two Theory of Mind tests as in Study 1, but in addition they received a test of evidential comprehension.

The Evidentiality Task. Two puppets, a dog and cat told 8 stories. The cat and the dog took turns telling the same story, one using PAST tense forms taken by native speakers to mean witnessed and the other marked with the non-witnessed evidential form. After each pair of stories, the child was asked the following question: 
Table 1. A sample story from the evidential task

The boy played in the yard with a ball.

He saw a cat and left the ball and started to run after the cat.

\section{BULGARIAN}

A

Момче-то играеше на двора с една топка.

boy- the play-3sgPT in yard with one ball

То видя една котка, остав-и топка-та

he see- $3 \mathrm{sgPT}$ one cat leave-3sg.PT ball-the

и започ-на дагони котка-та.

and start-3sg.PT run-after-3sgPT cat-the

B

Момче-то играе-ло на двора с една топка.

boy- the play-evid in yard with one ball

То видя-ло една котка, остави-ло топка-та и започна-ло да

he see- evid. one cat leave-evid. ball-the and start-evid. to

гони котка-та.

run-after-3sgPress.T cat-the

\section{ROMANI}

A

O čšavo khel-da andi bar jekh-e topka-sa.

the boy play-3sgPT3 in yeard one-INST ball-with-INSTR.

Ov dikh-la jekhe pisika, mukh-la $i$ topka thaj astar-da

he see-3sgPT one cat, leave-3sgPT the ball and start-3sgPT

te naš-el palal $i$ pisika.

to run-3sg.PT after the cat

B

O čšavo khel-da-lem andi bar jekh-e topka-sa

the boy play-3mPT-evid in yard one-INSTR ball-with-INSTR

Ov dikh-la-lem jekh-e pisika,

he see -3sg.PastT.evid. one cat

muk-la-lem $i$ topka thaj asarda-lem te

leave-3sgPT-evid. the ball and start-3sgPT-evid. to

naš-el pal i pisika.

run-3sg after the cat 
Who saw what happened: the dog or the cat?

In Bulgarian, children would have to understand that the form -ло is the mark of non-witnessed, and choose the other speaker. In Romani, children would have to understand that the form -lem is the marker of non-witnessed, and choose the other speaker. In this way the task is identical across languages.

Table 1 gives an example story in both forms in Bulgarian and in Romani.

\section{Results}

\section{Theory of Mind testing}

The data were recorded on score sheets and results entered into an Excel file. The various data from different ages and language groups were then compiled into SPSS format for analyses of variance. The total number of items correct out of four on the two false belief tasks was tallied for the dependent measure. A repeated measures analysis of variance was conducted with language of the task as the within-subjects variable, and age group of the child as the between-subjects variable. The language of the test was a significant variable: Romani children performed better in their L1, Romani, on the ToM tasks $(\mathrm{F}(1,20)=6.5, \mathrm{p}<0.02)$. The children also improved on False belief tasks with age. Age is a significant effect also for this group $(\mathrm{F}(2,20)=3.6, \mathrm{p}=0.045)$. However, the average performance was quite low, in keeping with the young ages tested.

In the second study, the children averaged six months older than in the first study. Results for the bilingual group of Roma children were tallied in the same way and subjected to the same analysis of variance. Table 2 shows the basic data from Study 2 .

Table 2. Results from Study 2

Language groups

Age groups

\begin{tabular}{lccc} 
& $3 ; 6-4 ; 0$ & $4 ; 0-4 ; 6$ & $4 ; 6-5 ; 0$ \\
\hline Average Performance on Classic Theory of Mind Tests (Total points=4) & \\
Monolingual Bulgarian children in L1 & 2.00 & 2.69 & 3.26 \\
Bilingual Romani-Bulgarian children in L1 & 1.55 & 2.27 & 3.00 \\
Bilingual Romani-Bulgarian children in L2 & 1.63 & 2.27 & 2.43 \\
\hline
\end{tabular}

Average Performance on Evidentials task (Total points=8)

\begin{tabular}{llll} 
Monolingual Bulgarian children in L1 & 3.8 & 5.0 & 6.5 \\
Bilingual Romani-Bulgarian children in L1 & 5.7 & 6.5 & 7.0 \\
Bilingual Romani-Bulgarian children in L2 & 6.8 & 5.1 & 6.4 \\
\hline
\end{tabular}


Figure 1. The L1 (Romani) performance of Roma children in the two studies on ToM tasks

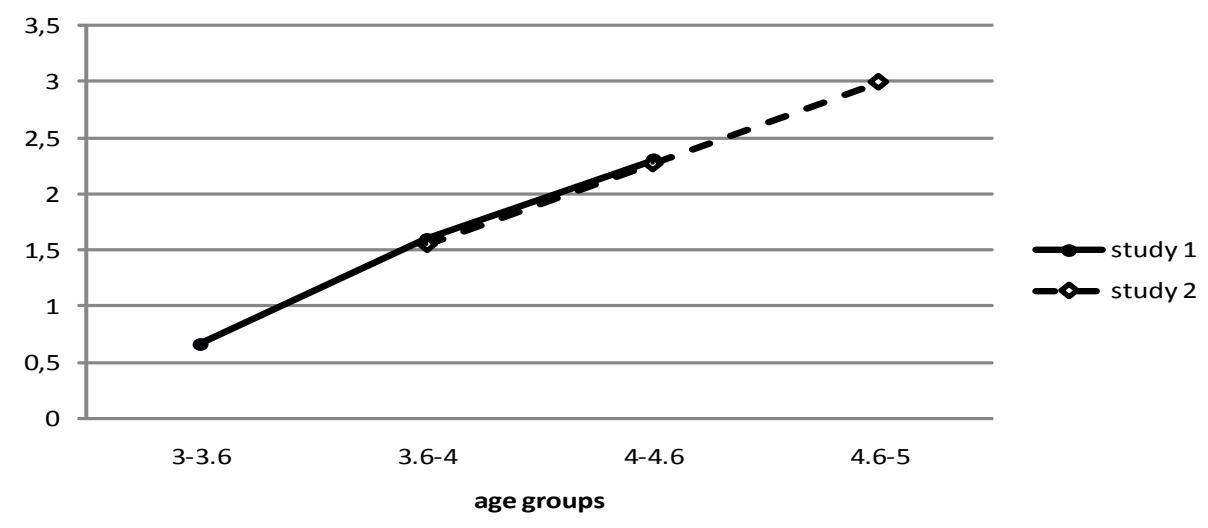

Figure 2. The L2 (Bulgarian) performance of Roma children in two studies on the ToM tasks

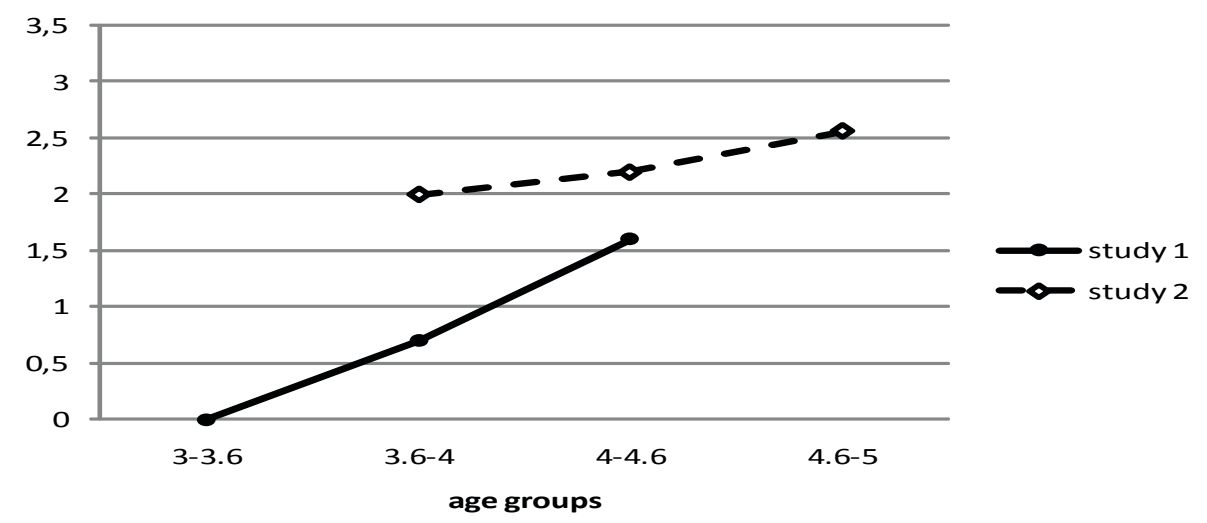

Figure 3. ToM performance in Bulgarian by age

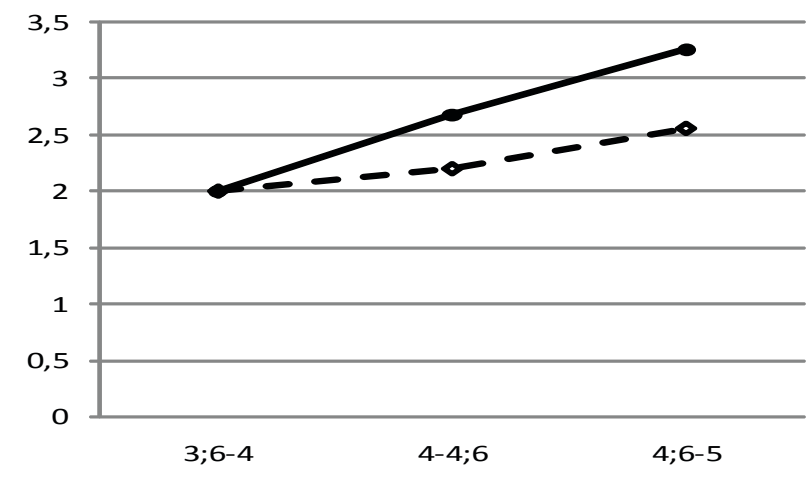

- Romani-Bulgarian bilinguals

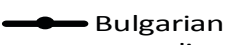
monolinguals

age groups 
Figure 4. The performance of the groups on ToM in their L1 (Study 2)

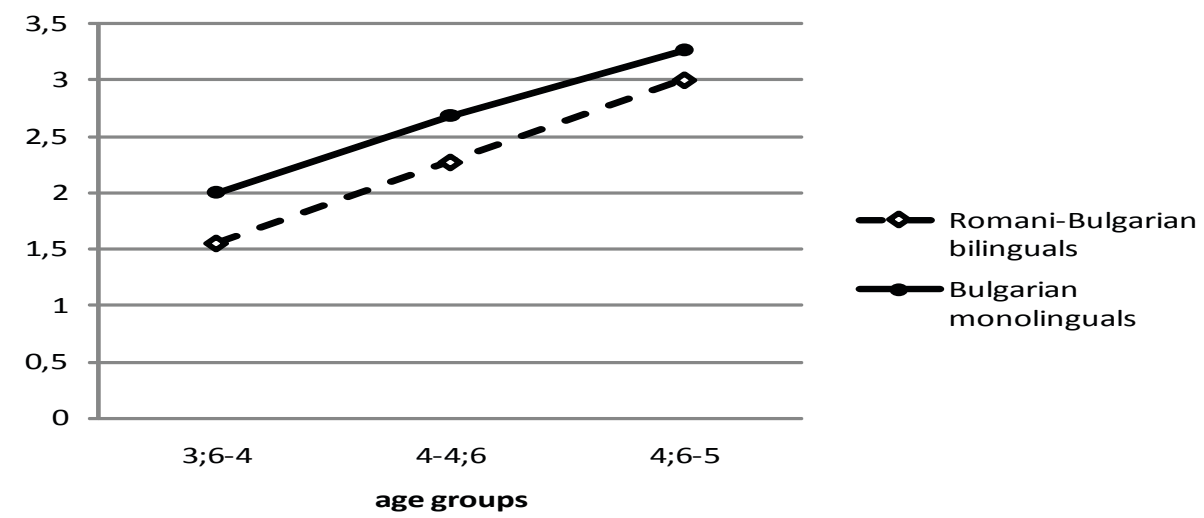

The findings from Study 2 revealed no significant differences between performance in L1 or L2 on the total false belief score. That is, by age 3;6, the bilingual children seem to be performing equivalently in their two languages on this task. Figure 1 reveals that the Roma children were equivalent in Study 1 and Study 2 despite being drawn from different areas of the country and speaking different dialects of Romani.

As one can see, the results from study 2 are concordant with the results of the children from study 1 . The results show that ToM performance in L1 develops with age in both groups in a similar way.

Nevertheless, the bilingual groups in Study 1 and Study 2 do perform differently in their L2 - Bulgarian. As can be seen in Figure 2, the children in Study 2 do better on average than the children in Study 1 at the same age in their L2Bulgarian.

The next comparison is with the monolingual Bulgarian children studied in Study 2, considering performance first on the same task, namely ToM in Bulgarian. The data were subjected to a mixed analysis of variance with the dependent variable of total ToM score as before, but now both age and language group -monolingual or bilingual- as the group variables. Both groups show improved performance with age $(F(2,78)=12.46, p<0.001)$. After the first age group, the monolingual children make more rapid progress in ToM than the bilingual children, as shown by the increasing gap in Figure $3(\mathrm{~F}(2,75)=5.85, \mathrm{p}<0.02)$.

Figure 4 shows the L1 performance of Bulgarian monolinguals and RomaniBulgarian bilinguals on the ToM task. The difference in performance between groups is not significant $(F(2,78)=3.01, p=0.08)$, though there is a trend for the monolinguals to be slightly better. There is no evidence of a bilingual advantage. 
Figure 5. The performance of the groups on L1 evidentials

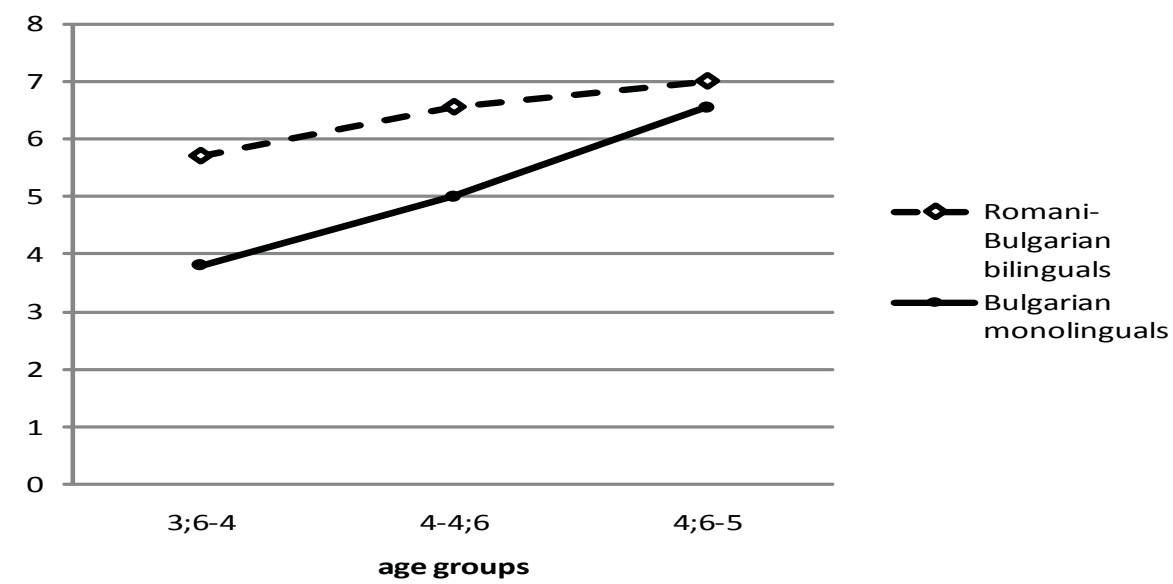

\section{Evidential understanding}

Consider now the performance of the groups on evidentials in L1 from the second study. This is shown in Figure 5.

Figure 5 shows that the Roma children have much better results on the evidential task than the Bulgarian children. The difference between the groups is significant $(\mathrm{F}(1,114)=11.7, \mathrm{p}<0.001)$. Furthermore, the performance on Bulgarian evidentials is also very good for these Roma children even though it is their L2. Even if we assume the suspiciously high performance at the youngest age is a statistical artifact, their performance parallels that of the L1 learners.

Finally, we asked about the relationship between ToM performance and evidential comprehension in each group and each language, partialing out the improvement with age. The correlation between L1 evidential comprehension and ToM performance, partialing out age, is significant and positive for the Bulgarian monolinguals: $\mathrm{r}(42)=0.36, \mathrm{p}<0.02$. However, the correlation is not significant for the Romani bilinguals in Romani (r (36) $=-0.09$, n.s.). This difference in relationship does not seem to be a difference between the languages, because in the L2, Bulgarian, of the Roma children, there is also no significant correlation between ToM and L2 evidentials (r $(33)=-0.08$, n.s.).

\section{Discussion}

\section{Theory of Mind}

Bilingual children are better at the ToM tasks in their L1 than their L2 at age 3;0, but the difference disappears by 3;6. There is no advantage of bilingualism per se, i.e. compared to monolinguals, in verbal ToM, in this study. The contrast in 
L2 performance between Study 1 and 2 remains unexplained: the second group seems to be more proficient in Bulgarian at the same ages. One might speculate that because the dialect of Romani and Bulgarian both have evidential markings, that there is less distance between L1 and L2 for the subjects in Study 2 than in Study 1. Certainly the bilinguals in Study 2 show strong performance in evidentials in both of their languages.

\section{Evidentials}

Why do the Romani-speaking children have better results than Bulgarian children in evidential comprehension? In this particular Romani dialect the morpheme -lem functions as an evidential marker only, while in Bulgarian the morpheme $-\pi,-л а,-л о$ has also a function of Past Imperfect Tense (Aorist). So it is very possible that the Bulgarian children by these ages still do not differentiate when the morphemes have a function of evidential, namely marking source of knowledge, versus a function of Aorist tense/aspect. The Romani speakers appear to be learning the evidential -lem at a faster rate than the Bulgarian monolinguals learn their L1 evidentials. We argue that this is because -lem is an unambiguous morpheme rather than one that also carries past tense. It may also be assisting the bilingual speakers to distinguish the evidential meanings in Bulgarian.

\section{ToM and Evidentials}

The relation of evidentiality and ToM is not yet clear. There is a stronger rationale for a relationship between evidentiality and the seeing-knowing distinction than with false belief reasoning (Papafragou et al, 2007), but a distinction in who saw and who did not see is also foundational for keeping track of beliefs in the false belief tasks. Studies of other languages have so far failed to find a relationship between false belief reasoning and mastery of evidentiality, but here we did find a relationship in the Bulgarian monolinguals, which is a puzzling result. It does not seem to be due to special properties of Bulgarian per se, because the bilingual Roma children who speak Bulgarian do not show the connection. Clearly more work is needed to confirm and clarify this result.

Previous work has also failed to find an enhanced effect on ToM in children speaking an evidential language (Papafragou et al, 2007). The data in this paper are compatible with data from the large cross-linguistic meta-analysis by Wellman, Cross and Watson (2003), in that both groups are beginning to pass the false belief tasks more consistently in the mid-four year old age range. This is perhaps especially surprising for the Roma children, whose parental education level is quite low, and who are generally from the lower socio-economic classes. Some work in the US and the UK has found that socio-economic status, especially parental education, can be a factor in the age at which children succeed in ToM and related tasks (Cutting \& Dunn, 1999; Pears \& Moses, 2003). Nevertheless, the more impressive finding is how much constancy there is in 
the general age at which false belief tasks are mastered, despite considerable cultural and linguistic difference.

\section{References}

Aikhenvald, A.Y. (2004). Evidentiality. New York: Oxford University Press.

Aksu-Koç, A., \& Alici, D.M. (2000). Understanding sources of beliefs and marking of uncertainty: Child's theory of evidentiality. In E.V. Clark (Ed.), Proceedings of the 30th Annual Child Language Conference (pp. 123-130). Stanford: Stanford University.

Aksu-Koç, A. (1988). The Acquisition of Aspect and Modality: The Case of Past Reference in Turkish. Cambridge: Cambridge University Press.

Astington, J.W., \& Baird, J.A. (2005). Representational development and false-belief understanding. In J.W. Astington \&. J.A. Baird (Ed.), Why language matters for theory of mind (pp. 163-185). New York: Oxford University Press.

Bartsch, K., \&Wellman, H. (1997). Children Talk About the Mind. New York: Oxford University Press.

Bialystok, E. \& Senman, L. (2004). Executive Processes in Appearance-Reality Tasks: The Role of Inhibition of Attention and Symbolic Representation. Child Development, 75, 562-579.

Carlson, S. \& Meltzoff, A. (2008). Bilingual Experience and Executive Functioning in Young Children. Developmental Science, 11 (2), 282-298.

Choi, S. (1995). The development of epistemic sentence-ending modal forms and functions in Korean children. In J. Bybee \& S. Fleischman (Eds.), Modality in Grammar and Discourse (pp. 165-204). Amsterdam: John Benjamins.

Cutting, A.L., \& Dunn, J. (1999). Theory of mind, emotion understanding, language, and family background: Individual differences and interrelations. Child Development, 70, 853-865.

de Villiers, J. (2005 ). Can Language Acquisition Give Children a Point of View. In J.W. Astington \& J.A. Baird (Eds.) Why Language Matters for Theory of Mind. New York: Oxford University Press.

de Villiers, J. \& Pyers, J. (2002). 'Complements to Cognition: A Longitudinal Study of the Relationship between Complex Syntax and False-Belief Understanding'. Cognitive Development, 17, 1037-1060.

de Villiers, J., Speas, P., Garfield, J., \& Roeper, T. (2007). Preliminary Studies of Acquisition of Tibetan Evidentials, Symposium paper, SRCD Convention, Boston, April (2007).

de Villiers, J., Garfield, J., Gernet Girard, H., Roeper, T., \& Speas, P. (2009). Evidentials in Tibetan: Acquisition, semantics and cognitive development. In Fitneva, S. \& Matsui, T. (Eds.), Evidentiality: A window into langauge and cognitive development. New Directions for Child and Adolescent Development, 125, 29-48. 
de Villiers, P. (2005). The Role of Language in Theory-of-Mind Development: What Deaf Children Tell Us, In J.W. Astington \& J.A. Baird (Eds.), Why Language Matters for Theory of Mind (pp.186-219) New York: Oxford University Press. de Villiers, P., de Villiers, J., \& Hobbs, K. (2009). False belief reasoning in low-income bilingual Hispanic preschoolers: Is there an effect of bilingualism? Paper in a symposium on Cognitive Effects of Bilingualism at the Society for Research in Child Development (SRCD) Biennial Convention, Denver, CO.

Fitneva, S.A. (2007). Bulgarian children's awareness and use of evidentials. Paper presented at the Society for Research in Child Development

Fitneva, S.A. (2008). The role of evidentiality in Bulgarian children's reliability judgments. Fournal of Child Language, 35 (4), 845-868.

Goetz, P. (2003). The Effects of Bilingualism on Theory of Mind Development. Bilingualism: Language and Cognition, 6 (1), 1-15.

Harris, P. (2005). Conversation, Pretense, and Theory of Mindmmm. In J.W. Astington \& J.A. Baird (Eds.) Why Language Matters for Theory of Mind (pp:70-83). New York: Oxford University Press.

Jaques, S. \& Zelazo, P. (2005) Language and the development of cognitive flexibility. In J.W. Astington \& J.A. Baird (Eds.) Why Language Matters for Theory of Mind (pp:144-183). New York: Oxford University Press.

Kovács, A. (2009). Early Bilingualism Enhances Mechanisms of False-Belief Reasoning. Developmental Science, 12 (1), 48-54.

Milligan, K., Astington, J.W., \& Dack, L.A. (2007). Language and Theory of Mind: Meta-Analysis of the Relation Between Language Ability and False-belief Understanding. Child Development, 78 (2), 622-646.

Nelson, K. (2005). Language Pathways into the Community of Minds. In J.W. Astington \& J.A. Baird (Eds.) Why Language Matters for Theory of Mind (pp. 2649) NewYork: Oxford University Press.

Ozturk, O. \& Papafragou, A. (2007). The Acquisition of Evidentiality in Turkish. 31st Annual Boston University Conference on Language Development. Somerville, MA: Cascadilla Press.

Papafragou, A., Li, P., Choi, Y., \& Han, C. (2007). Evidentiality in language and cognition. Cognition, 103, 253-295.

Papafragou, A. \& Ozturk, O. (2007). Children's acquisition of evidentiality, 31st Annual Boston University Conference on Language Development. Somerville, MA: Cascadilla Press.

Pears, K.C. \& Moses, L.J. (2003). Demographics, parenting, and theory of mind in preschool children. Social Development, 12, 1-20.

Pearson, B.Z., Fernandez, M. C., \& Oller, D.K. (1993). Lexical development in bilingual infants and toddlers: Comparison to monolingual norms. Language Learning, 43, 93-120.

Speas, M. (2004). Evidentiality, Logophoricity and the Syntactic Representation of Pragmatic Features. Lingua, 114 (3), 255-276. 
Woolfe, T., Want, S., \& Siegal, M. (2002). Signposts to Development: Theory of Mind in Deaf Children, Child Development, 73, 768-778.

Wellman, H.M., Cross, D., \& Watson, J. (2001). Meta-analysis of theory-of-mind development: The truth about false belief. Child Development, 72, 655-684. 